\section{An Aceto-Carmine Staining Technique for the Ectocarpales}

THE following technique has been devoloped for the study of chromosomes in specins belonging to the order Ectocarpales and has been used successfully on Ectocarpus, Giffordia and Pylaiella spp.

Fixation. Material is fixed in 95 per cent ethyl alcohol and glacial acetic acid, $3: 1$, to which is added a sufficient quantity of concentrated aqueous ferric chloride solution to impart a pale yellow colour to the fixative. Fixation is complete in $12-24 \mathrm{hr}$.

Storage. After fixation, material is washed free of the fixative in 70 per cent ethyl alcohol. It may then be stored in 70 per cent alcohol for $\varepsilon$ period of up to six months, preferably in a refrigerator, without serious deterioration.

Maceration. Material to be stained is pretreated as follows: A small portion of thallus is washed in distilled water, arranged on a clean slide, and mounted in a few drops of 100 vol. (about 30 per cent $w / v$ ) hydrogen peroxide solution. 'The slide is then warmed gently for about 30 sec., the material covered by an albumenized cover-glass, and the preparation squashed between three thicknesses of filter paper. The slide is then inverted in a ridged dish containing 2 per cent acetic acid until the cover-glass, bearing the material, floats off.

Staining. The cover-glass is transferred from the 2 per cent acetic acid to a watch-glass filled with aceto-carmine ${ }^{1}$. The stain is then heated until stearn and acetic acid vapour are given off, and maintained at this temperature, just short of boiling point, for $5-10 \mathrm{~min}$.

Differentiation. The cover-glass is then immersed in 45 per cent acetic acid and the material differentiated in this until o pale pink colour is obtained. This process is usually complete in $1-2 \mathrm{~min}$.

Dehydration. The material is dehydrated in 95 per cent ethyl alcohol followed by two changes of absolute alcohol. Clearing is in 'Euparal' essence and the material is mounted in 'Euparal'.

When the specimen to be stained has cell walls particularly tough and rosistant to squashing, or, if it is especially rich in chromatophores and other extra-nuclear cell components which can obscure nuclear details, thon a 3 por cent aqueous solution of sodium carbonato may be used as a macerating agent. Sodium carbonate, in 6 per cent solution, was suggested by Naylor ${ }^{2}$ as an aid to squashing species of Fucales, and it is undoubtedly efficient in its action on the algin, which constitutes the greater part of the cell wall, but its strong alkalinity $(p \mathrm{H} 11 \cdot 6)$ can cause partial degradation of the chromosomes. This has the effect of blurring their outlines and thus making it difficult to distinguish between one chromosome and its neighbours. Sodium carbonute should therefore be used with cantion. Material is mounted in a fow drops of tho solution, warmed very gently, squashed as described, and inverted in the 2 per cont acetic acid. It is important that the cover-glass be floated off in an acid medium since the high alkalinity of the carbonate can also cause precipitation of carmine particles from the aceto-carmine stain, unloss first neutralized.

When the plant material is very delicate, and its extra-nuclear cell components are not numerous enough to obscure nuclear details, uso of a macerating agent may be dispensod with, the material being arranged on the slide, mounted, and squashed in a drop of water.

This technique provides an casy and reliable method for the oxamination of the very small chromosomes found in the Ectocarpales. Because of its speed, this method is also useful in distinguishing haploid and diploid plants in an order the species of which often show an alternation of morphologically identical generations.

Marine Biological Station,

(University of Liverpool),

Port Erin, Isle of Man

${ }^{2}$ Darijngton, O. D., and La Cour, L. K., The Handling of Chromosomes, third ed. (Allen and Unwin, London, 1960).

" Naylor, M., Nature, 180, 46 (1957).

\section{MICROBIOLOGY}

\section{Reversion of Spheroplasts produced by Lysozyme into Rods in Proteus vulgaris}

THE modes of regeneration of large bodies formod by the action of penicillin are well known to-day. This is not so, however, for spheroplasts produced by lysozyme. The possibility of their reversion to the basillary form is quotod by Zinder and Arndt ${ }^{1}$, although it is donied by others?. So far as we know, no morphological study of this reversion has yet been publishod. If lysozyme and ponicillin act on the samo layor of the cell wall ${ }^{3}$, the corresponding forms might bo expected to behave in the same way during the regeneration process.

Wo have investigated the rogeneration of lysozymespheroplasts of Proteus vulgaris prepared according to Kohn's method'. The best rosults were obtained when the culture was frozen for $12 \mathrm{hr}$. We found that, 30 min. after thawing, more than 90 por cont of rods had been converted into spheres. This culture was washed with broth containing $0.2 M$ sucrose and then inoculated on to thin agar blocks covered with covorslips. 'PPLO-agar' (Difco) enriched by yeast extract was also found suitable.

Only in a small pereentago of cases did regeneration follow the same course as with large bodies, that is, via the large long bodies ${ }^{5}$ (Fig. 1). In the overwhelming majority of cases it was as follows (Fig. 2): the sphere grew in bipolar fashion in an oval formation which then divided by binary fission. Both formations grow in longth and divided in a direction cross-wise to the former division. The formations increased in

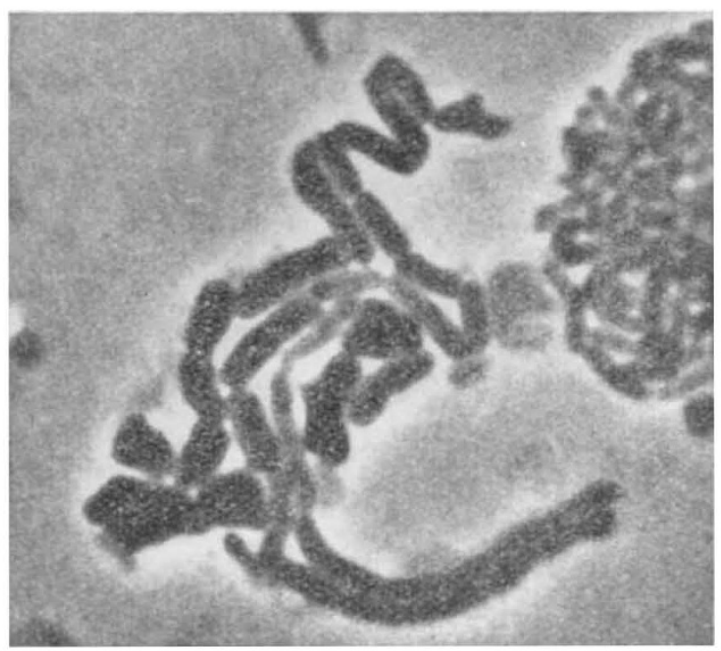

Fig. 1. Large long body producing bacterial forms by successive fragmentation. Phase-contrast microscopy. (x 6,500) 